\title{
ALIH TUTUR BAHASA INGGRIS DALAM OXFORD ENGLISH DAILY CONVERSATION
}

\author{
I Gusti Ayu Agung Sintha Satwika \\ Universitas Udayana \\ agung_sintha@yahoo.com
}

\begin{abstract}
ABSTRAK
Penelitian ini bertujuan untuk menemukan dan menganalisis alih tutur pada bahasa Inggris. Data pada tulisan ini didapatkan dari sebuah video yang berjudul Oxford English Daily Coversation. Penelitian ini dilakukan dengan menerapkan metode kualitatif dimana pembahasan disajikan dalam bentuk kalimat deskriptif. Data dari penelitian ini dikumpulkan dengan menerapkan metode simak dan catat. Hasil dari penelitian ini menunjukkan bahwa alih tutur dalam bahasa Inggris dapat ditandai oleh intonasi, penekanan kata, dan jeda. Sinyal-sinyal tersebut mengindikasikan apakah penutur mengambil, mempertahankan atau memberikan hak berbicara
\end{abstract}

Kata kunci: alih tutur, penutur, mitra tutur

\begin{abstract}
[Title: Turn-Taking in English found in Oxford English Daily Conversation] This research aims at investigating and analyzing the turn-taking in English conversation. The data of this writing were collected from a video entitled Oxford English Daily Conversation. This study was conducted by applying the qualitative method of which the discussion was presented descriptively. The data of this study were obtained by using observation and note taking technique. The result of this study indicates that turn-taking in English conversation can be signaled by intonation, stress of word, and pause. Those signals indicate whether the speaker is taking, holding, or yielding the conversation floor.
\end{abstract}

Keywords: turn taking, speaker, addressee

\section{PENDAHULUAN}

Manusia berkomunikasi untuk untuk menyampaikan pesan, mengekspresikan perasaan dan emosi mereka. Komunikasi merupakan pengiriman dan penerimaan pesan atau berita antar dua orang atau lebih sehingga pesan yang dimaksud dapat dipahami (Alwi \& dkk., 2002). Berkaitan dengan hal ini, Chaer dan Agustina (1995) berpendapat bahwa penggunaan bahasa dalam komunikasi perlu memperhatikan dua aspek, yaitu aspek linguistic dan paralinguistic (Chaer \& Agustina, 1995). Fonologi, morfologi dan sintaksis merupakan cakupan dari aspek linguistik. Sedangkan, aspek paralinguistic mencakup unsur suprasegmental seperti tekanan, nada, serta intonasi.

Komunikasi langsung dapat dilakukan dengan percakapan. Menurut Wardaugh percakapan berarti kegiatan kooperatif dalam arti melibatkan dua pihak atau lebih. Dalam percakapan, posisi partisipan yang terlibat didalamnya (penutur dan mitra tutur) tidak tetap (Ronald, 1986). Artinya, posisi penutur dan mitra tutur akan saling bertukar. Misalnya pada percakapan yang melibatkan dua 
pihak (A dan B). Saat A sebagai penutur (berbicara), maka posisi B adalah sebagai mitra tutur (pendengar) yang menunggu giliran untuk berbicara. Selanjutnya, saat B menjadi penutur, posisi A adalah sebagai mitra tutur yang mendengarkan B, dan menunggu giliran untuk berbicara. Dari penjelasan ini dapat dilihat bahwa terdapat pergantian giliran berbicara atau sering disebut alih tutur. Penjelasan ini diperkuat oleh Mey yang menyatakan peralihan dalam percakapan adalah pergeseran arah aliran berbicara yang merupakan ciri khas pada percakapan (Mey, 2001).

Dalam percakapan terdapat unsur penting yang disebut floor atau hak berbicara. Apabila seseorang memegang hak berbicara, maka seseorang tersebut memiliki kontrol dalam suatu percakapan (Yule, 2014). Hak berbicara dan kesempatan berbicara dalam percakapan dapat dikaji melalui fitur fonologi prosodic yang meliputi intonasi, penekanan, dan jeda (Kuhlen dalam Pennington, 2007). Partisipan dalam percakapan harus memahami siapa yang memiliki hak bicara, kapan harus masuk dalam percakapan, berapa lama harus menunggu untuk menjawab, kapan harus diam, dan kapan harus berbicara. Hal-hal ini perlu diperhatikan untuk menghindari benturan-benturan saat berkomunikasi agar pesan yang akan disampaikan dapat tersampaikan dengan baik.

\section{METODE}

Penelitian ini menekankan pada mekanisme alih tutur berdasarkan fitur fonologi prosodik seperti intonasi, tekanan, dan jeda pada sebuah video berbahasa Inggris yang berjudul Oxford English Daily Conversation. Data dari penelitian ini adalah ujaran-ujaran lisan dalam percakapan sehari-hari dalam bahasa Inggris. Metode simak dan catat digunakan untuk mengumpulkan data yang berupa ujaran lisan-ujaran lisan bahasa Inggris yang mengandung fenomena alih tutur. Simak yang dimaksud disini adalah menyimak penggunaan bahasa (Sudaryanto, 2015). Pada praktiknya, metode simak itu diwujudkan dengan penyadapan. Untuk mendapatkan data, si peneliti menggunakan teknik sadap, dengan kemampuannya menyadap penggunaan bahasa seseorang atau beberapa orang dalam video percakapan sehari-hari dalam bahasa Inggris yang didapatkan dari situs berbagi video youtube.

Dengan adanya kemajuan teknologi, teknik rekam tidak digunakan dalam merekam percakapan berbahasa Inggris tersebut untuk mengamati ujaran-ujaran yang dapat didengar serta bahasa-bahasa non verbal yang dapat dilihat. Hal ini dikarenakan percakapan sehari-hari dalam bahasa Inggris tersebut sudah terekam dalam bentuk video dan diunggah ke situs berbagi video Youtube. Sehingga, kegiatan menyadap ini dapat dilakukan dengan tidak berpartisipasi saat menyimak, yang dapat disebut dengan teknik simak bebas libat cakap (SBLC). Dalam penggunaan teknik ini, si peneliti tidak terlibat dalam dialog yaitu tidak ikut serta dalam proses pembicaraan orang-orang yang saling berbicara dalam bahasa Inggris. Si peneliti tidak bertindak sebagai penutur ataupun mitra tutur dalam percakapan tersebut; namun sebagai pemerhati yang dengan tekun mendengarkan apa yang dikatakan oleh orang-orang yang terlibat dalam dialog bahasa Inggris tersebut. Dalam hal ini konsep dialog sama dengan interaksi lingual yang pada pokoknya melibatkan dua pihak yang berlaku sebagai penutur dan mitra tutur yang lebih bersifat komunikatif, yaitu dua arah dan timbal balik (Sudaryanto, 2015).

Selain teknik simak bebas libat cakap (SBLC), teknik catat juga diaplikasi- 
kan sebagai teknik lanjutan dalam pengumpulan data penelitian ini. Teknik catat ini digunakan untuk mentranskripsi ujaran-ujaran para partisipan dalam video yang sudah terpilih yang menunjukkan adanya fenomena alih tutur. Kemudian, data yang sudah ditranskripsi tersebut diklasifikasikan berdasarkan hak berbicara. Selanjutnya, penelitian ini mengaplikasikan teori alih tutur oleh Mey (2001) dan teori fonologi prosodic oleh Kuhlen dalam Pennington (2007).

\section{PEMBAHASAN}

Menurut Mey (2001), ada tiga strategi dasar alih tutur yang dapat ditemukan dalam data, yaitu menjadi mengambil hak berbicara (taking the floor), mempertahankan hak berbicara (holding the floor) dan memberikan hak berbicara (yielding the floor). Selain itu, alih bicara juga ditentukan oleh factor fonologis, dalam hal ini adalah fonologi prosodic, yang meliputi penekanan, pengaturan waktu dan ritme, susunan nada dan tingkat kenyaringan (Kuhlen dalam Pennington, 2007). Contoh-contoh dan pembahasan alih tutur tersebut dapat dijabarkan sebagai berikut.

\section{Mengambil Hak Berbicara (Taking the Floor)}

Dalam hal ini, mengambil hak berbicara adalah partisipan dalam percakapan memiliki inisiatif untuk mulai berbicara. Ada beberapa cara untuk mengambil hak berbicara dalam percakapan, misalnya dengan memulai percakapan dan melakukan interupsi (Mey, 2001).

\section{Memulai Percakapan}

Pengambilan hak berbicara pada percakapan dapat dilakukan saat percakapan dimulai oleh penutur 1. Peristiwa alih tutur yang dilakukan dengan mengambil hak berbicara (memulai percakapan) dapat dilihat pada contoh dibawah ini.

Mrs. Drake $\quad$ Look at the time! Julia! It's half past seven. Your train's at quarter to eight! $\uparrow$
Julia

Potongan percakapan di atas terjadi antara Ibu dan anak yaitu Mrs. Drake dan Julia. Hari itu adalah hari pertama Julia bekerja di kantor barunya, yaitu Apex TV. Saat itu, waktu telah menunjukkan pukul 7.30 pagi, sedangkan kereta yang akan ditumpangi Julia ke kantor akan berangkat pada pukul 07.45. Oleh karena itu, Mrs. Drake mengambil hak berbicara dengan memulai percakapan dengan Julia. Mrs. Drake memberitahu Julia bahwa Julia harus bergegas agar tidak terlambat dengan cara menaikkan intonasi saat mengucapkan quarter to eight (pukul 7.45). Sinyal yang diberikan Mrs. Drake dapat diterima oleh Julia. Ini dibuktikan pada saat Julia mengatakan COMING!, dimana ujaran ini dicetak dengan huruf capital yang menegaskan bahwa Julia mengerti bahwa Mrs. Drake memintanya untuk bergegas agar tidak ketinggalan kereta.

\section{Interupsi}

Interupsi ini dilakukan karena penutur dua mengira bahwa penutur satu sudah selesai berbicara (Mey, 2001). Contoh terjadinya alih tutur pada percakapan dari penutur satu ke penutur dua dengan mengambil hak berbicara (interupsi) dapat dilihat sebagai berikut 
Vol. 2, No. 1, Januari 2018, 62

Available Online at https://ejournal.warmadewa.ac.id/index.php/kulturistik

DOI: dx.doi.org/10.22225/kulturistik.2.1.521

$\begin{array}{ll}\text { Tim } & \text { : Martha, can I have a word? } \\ \text { Martha } & \text { : Yes Tim, what is it? } \\ \text { Tim } & \text { : I haven't got an assistant for this afternoon, for the story of Carl Stalker. You know } \\ \text { the windows guy. } \\ \text { Martha } & : \text { Oh, yes. Well, who have we got? } \\ & \text { Ah, Chloe's away, Gita's on holiday (.) } \\ \text { Tim } & : / / \text { and everybody else is busy. But I have to have an assistant. }\end{array}$

Pada percakapan diatas, strategi yang digunakan oleh Tim untuk mengambil hak berbicara adalah dengan cara menginterupsi. Interupsi tersebut dilambangkan oleh symbol "//". Martha memberitahu tahu Tim bahwa Chloe dan Gita tidak ada di kantor. Pada saat Martha masih belum selesai berbicara, Tim sudah memotong pembicaraan Martha dengan mengatakan and everybody else is busy (dan yang lainnya sedang sibuk). Saat Martha mengatakan Gita's on holiday menandakan bahwa Martha sedang memerlukan waktu untuk mengingat siapa saja pada saat itu ada di kantor yang bisa direkomendasikan untuk menjadi asisten Tim. Oleh karena itu, Martha berhenti berbicara sejenak yang ditandai oleh symbol jeda "(.)". Namun, Tim mengambil alih hak bicara karena menganggap Rita sudah selesai berbicara. Hal ini juga diperkuat oleh Yule (2014) yang menyatakan bahwa alih tutur dapat terjadi apabila adanya kesenyapan atau jeda yang dilakukan penutur sebelumnya sehingga hak berbicara diambil oleh penutur selanjutnya. Pada contoh di atas, penutur sebelumnya adalah Martha, karena adanya kesenyapan sejenak maka penutur selanjutnya (Tim) mengambil alih hak berbicara dalam percakapan tersebut.

\section{Mempertahankan Hak Berbicara (Holding the Floor)}

Mempertahankan hak berbicara menandakan bahwa penutur ingin tetap berbicara dan mengontrol hak berbicara sejauh yang diperlukan oleh si penutur tersebut (Mey, 2001). Mempertahankan hak berbicara dalam percakapan antara Tim dan Julia seperti yang dapat dilihat pada contoh berikut.

$\operatorname{Tim}$

: Er, Julia (.) I, em wanted to say thank you for all your help when you know (.) and well, erm (.) would you like to go out for a meal sometime (.) just for

Julia you know, say thank you.

Pada percakapan di atas, Tim mengajak Julia untuk makan bersama. Namun, Tim terkesan gugup dan memerlukan waktu untuk memikirkan kata-kata yang tepat untuk digunakan. Hal ini terlihat saat tim berbicara melakukan jeda (.) yaitu sebanyak empat kali. Ini mengindikasikan bahwa tim mempertahankan hak berbicaranya, yaitu dengan melakukan jeda beberapa kali sebagai sinyal bahwa ia belum selesai berbicara dan memerlukan waktu untuk menyampaikan pesan secara utuh. Selain itu, pemertahanan hak berbicara juga dapat dilihat pada penggunaan em dan erm oleh Tim, yang bertujuan untuk mengindikasikan pada mitra tutur bahwa ia belum selesai berbicara, sehingga penutur selanjutnya belum bisa mengambil alih hak berbicara. Hal ini diperkuat oleh pendapat Yule yang menyatakan bahwa untuk mempertahankan hak berbicara, biasanya penutur mengisi jedanya dengan $u m$ atau $u h$, yang ditempatkan di dalam, tidak diakhir unit sintaksis (Yule, 2014). Penggunaan em dan erm pada contoh di atas memiliki fungsi yang sama dengan $u m$ dan $u$ h yaitu sebagai penanda bahwa penutur sebe- 
lumnya belum melepaskan hak berbicara.

\section{Memberikan Hak Berbicara (Yielding the Floor).}

Penutur dapat memberikan hak berbicara pada mitra tutur dengan cara memberikan pertanyaan atau pernyataan yang memicu respon dari mitra tutur tersebut, sehingga terjadi peristiwa alih tindak tutur (Mey, 2001).

(a)

$$
\begin{array}{ll}
\text { Martha } & \text { : Can we take a look at the diary for the week? NOW } \uparrow \\
\text { Rebecca } & : \text { Oh yes, all right }
\end{array}
$$

Pemberian hak berbicara dapat dilihat pada contoh di atas. Martha sebagai penutur memberikan hak berbicara pada Rebecca (mitra tutur) untuk mengecek jadwal kegiatan mingguan. Pada saat itu, Martha dalam keadaan panik dan tergesa-gesa karena masih banyak pekerjaan yang harus dilakukan. Martha memberikan hak berbicara dengan cara menekankan kata now yang ditandai dengan penggunaan huruf capital pada seluruh kata (NOW). Selain itu, pemberian hak berbicara ini diperkuat oleh intonasi naik yang ditandai oleh tanda panah vertikal. Mitra tutur dalam percakapan ini menangkap sinyal tersebut, sehingga ia mengambil hak berbicara dengan memberikan respon Oh yes, all right.

(b)

Caller

: This is Angus Moon from The Modern Woman Magazine. We'd like to do an article on the job of a personal assistant.

Rebecca : : uh huh

Caller : Martha Mc Kay's an old friend of mine and she says that you are a wonderful P.A.

Rebecca memberikan hak berbicara pada si penelepon dengan mengucapkan $u h$ huh menggunakan intonasi turun. Ujaran dengan intonasi turun ini memberikan sinyal pada si penelepon bahwa Rebecca ingin memberikan hak berbicara agar dapat mendengarkan informasi yang akan disampaikan oleh si penelepon tersebut secara utuh. Sinyal yang diberikan Rebecca ini ditanggapi dengan baik oleh si penelepon. Hal ini dibuktikan dengan si penelepon menerima hak berbicara tersebut dengan memberitahukan maksud dan tujuannya menghubungi Rebecca melalui telepon. Ada indikasi vokal yang disebut sinyal backchannel yaitu jenis-jenis penanda yang memberikan umpan balik terhadap penutur yang sedang berbicara, misalnya $u h-u h$, yeah, $\mathrm{mmm}$ agar penutur tetap menggunakan hak berbicaranya dalam suatu percakapan (Yule, 2014). Pada contoh di atas, dapat dilihat bahwa Rebecca menggunakan penanda umpan balik uh-huh untuk memberikan sinyal kepada mitra tutur untuk mengambil hak berbicara setelah mendengar penanda umpan balik yang dilontarkan oleh Rebecca.

(c)

$\begin{array}{ll}\text { Rebecca } & \text { : What's the date today, Tim? (1) } \\ \text { Tim } & \text { : What? (2) } \\ \text { Rebecca } & \text { : Today's date, what is it? (3) } \\ \text { Tim } & \text { : Er, it's the } 4^{\text {th }} \text { of October (4) } \\ \text { Rebecca } & \text { : And what do you know about the } 4^{\text {th }} \text { of October? (5) } \\ \text { Tim } & \text { : It's the day after the } 3^{\text {rd }} \text { of October (6) } \\ \text { Rebecca } & \text { : Try again, Tim. Think of your girlfriend } \uparrow(7) \\ \text { Tim } & \text { : Oh, No. It's Ellie's birthday! (8) }\end{array}$


Vol. 2, No. 1, Januari 2018, 64

Available Online at https://ejournal.warmadewa.ac.id/index.php/kulturistik

DOI: dx.doi.org/10.22225/kulturistik.2.1.521

Percakapan di atas juga menunjukkan adanya pemberian hak berbicara dari Rebecca, si penutur kepada Tim si mitra tutur. Dalam percakapan tersebut Rebecca berusaha memberikan Tim petunjuk bahwa hari itu, tanggal 4 Oktober adalah hari ulang tahun Ellie, kekasih Tim. Namun, Tim kesulitan menerima petunjuk yang diberikan oleh Rebecca. Kesulitan Tim dalam menerima petunjuk tersebut terlihat pada ujaran baris ke (2), (4), (6). Oleh karena itu, Ellie menaikkan intonasi pada akhir ujaran saat mengucapkan girlfriend. Sinyal yang diberikan Rebecca dapat diterima oleh Tim. Ini dibuktikan pada ujaran (8) dimana Tim akhirnya menyadari bahwa tanggal 4 Oktober adalah hari ulang tahun kekasihnya, Ellie.

(d) Julia : So let me see, there's the room, and the kitchen, and the bathroom, and the toilet are in the hall

Mr. Jackson $\quad:$ Yes, that's right. You share them with the people upstairs. They're very nice people

Alih tutur dari Julia ke Mr. Jackson dapat dilihat pada contoh percakapan di atas. Pada saat itu, Julia sedang mencari apartemen yang dekat dengan kantornya agar tidak terlambat. Lalu, Julia menemukan sebuah apartemen yang sesuai dengan kebutuhannya. Pada percakapan di atas, Julia menyatakan pernyataan bahwa ada kamar, dapur, serta kamar mandi dan toilet ada di koridor. Pada akhir ujaran, Julia menggunakan intonasi turun. Ini mengindikasikan bahwa pernyataan Julia tersebut merupakan sinyal agar mendapatkan respon dari Mr. Jackson bahwa apakah apa yang diujarkan oleh Julia tersebut (mengenai) fasilitas apartemen benar atau salah. Sinyal tersebut ditangkap oleh Mr. Jackson, yaitu dibuktikan saat ia menerima hak berbicara dengan mengatakan $Y$ es, that's right.

(e)

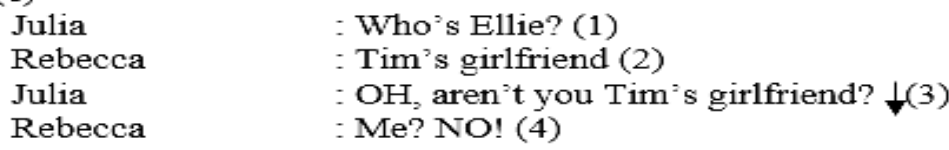

Pada percakapan dia atas, dapat dilihat bahwa ada perpindahan hak berbicara. Julia merupakan pegawai baru di Apex TV. Pada awalnya, Julia mengira bahwa Rebecca adalah kekasih Tim. Namun, Julia mendengar bahwa Tim akan membelikan cincin untuk Ellie. Lalu, Julia bertanya kepada Rebecca siapa Ellie. Pada ujaran (3) terdapat kata oh. Dalam bahasa inggris, oh merupakan kata seru yang digunakan saat bereaksi terhadap sesuatu yang belum diketahui sebelumnya (Hornby, 2010). Adanya penekanan kata oh pada ujaran (3) ditandai dengan huruf kapital. Penekanan ini menunjukkan bahwa Julia sangat terkejut saat mengetahui bahwa Rebecca bukanlah kekasih Tim. Selain itu, ujaran (3) berupa pertanyaan dan memiliki intonasi turun. Sehingga, hal ini memberikan sinyal pada mitra tutur (Rebecca) untuk menerima hak berbicara. Pada ujaran (4) kata no juga diberi penekanan, dan dicetak dengan huruf kapital untuk menegaskan bantahan bahwa Rebecca bukanlah kekasih Tim.

\section{SIMPULAN}

Dari pembahasan di atas, dapat disimpulkan bahwa partisipan dalam percakapan dapat mengambil, mempertahankan, dan memberikan hak berbicara. Seseorang mengambil hak bicara dalam percakapan dengan memulai suatu percakapan dan melakukan interupsi. Mengambil hak berbicara dengan cara 


\section{Lisulturisiolink \\ KULTURISTIK JURNAL BAHASA \& BUDAYA}

Vol. 2, No. 1, Januari 2018, 65

Available Online at https://ejournal.warmadewa.ac.id/index.php/kulturistik

DOI: dx.doi.org/10.22225/kulturistik.2.1.521

memulai percakapan dilakukan dengan cara memperingatkan sesuatu kepada mitra tutur. Sedangkan, pengambilan hak berbicara dengan melakukan interupsi dapat terjadi karena penutur sebelumnya melakukan jeda, Oleh karena itu penutur selanjutnya mengambil hak berbicara karena mengangap penutur sebelumnya sudah selesai berbicara. Mempertahankan hak berbicara dilakukan dengan cara melakukan jeda beberapa kali di sela-sela ujaran. Hal ini dilakukan karena penutur memerlukan waktu untuk memikirkan ujaran yang akan diutarakan. Selanjutnya, memberikan hak berbicara dilakukan dengan mengutarakan pertanyaan maupun pernyataan yang memicu respon dari mitra tutur. Mengambil, mempertahankan, maupun memberikan hak berbicara dipengaruhi oleh intonasi, penekanan kata, serta jeda.

\section{DAFTAR PUSTAKA}

Alwi, H., \& dkk. (2002). Kamus Besar Bahasa Indonesia. Jakarta: Balai Pustaka.

Chaer, A., \& Agustina, L. (1995). Sosiolinguistik Suatu Perkenalan A wal. Jakarta: Rineka Cipta.

Hornby, A. S. (2010). Oxford Advanced Learners's Dictionary. London: Oxford University Press.

Mey, J. L. (2001). Pragmatics: An Introduction. Oxford: Blackwell.

Pennington, M. C. (2007). Phonology in Context. New York: Palgrave Macmillan.

Ronald, W. (1986). An Introduction to Sociolinguistics. Oxford: Basil Blackwell.

Sudaryanto. (2015). Metode dan Aneka Teknik Analisis Bahasa. Yogyakarta: Sanata Dharma University Press.

Yule, G. (2014). Pragmatik. Yogyakarta: Pustaka Pelajar. 